\title{
BMJ Open Cohort profile : Bandim Health Project's (BHP) rural Health and Demographic Surveillance System (HDSS) - a nationally representative HDSS in Guinea-Bissau
}

\author{
Sanne Marie Thysen, ${ }^{\oplus 1,2,3,4}$ Manuel Fernandes, ${ }^{2}$ Christine Stabell Benn, ${ }^{1,2,3}$ \\ Peter Aaby, ${ }^{1,2}$ Ane Bærent Fisker ${ }^{\oplus 1,2,3}$
}

To cite: Thysen SM,

Fernandes M, Benn CS, et al. Cohort profile : Bandim Health Project's (BHP) rural Health and Demographic Surveillance System (HDSS)—a nationally representative HDSS in Guinea-Bissau. BMJ Open 2019;9:e028775. doi:10.1136/ bmjopen-2018-028775

- Pre-publication history and Additional material is published online only. To view please visit the journal online (http://dx.doi. org/10.1136/bmjopen-2018028775).

Received 22 December 2018 Revised 25 March 2019 Accepted 15 May 2019

Check for updates

(C) Author(s) (or their employer(s)) 2019. Re-use permitted under CC BY-NC. No commercial re-use. See rights and permissions. Published by BMJ.

${ }^{1}$ OPEN, Department of Clinical Research, University of Southern Denmark, Odense, Denmark

${ }^{2}$ Bandim Health Project, INDEPTH Network, Bissau,

Guinea-Bissau

${ }^{3}$ Research Center for Vitamins and Vaccines, Bandim Health

Project, Statens Serum Institut, Copenhagen, Denmark

${ }^{4}$ Center for Global Health, Aarhus University, Aarhus, Denmark

Correspondence to

Dr. Ane Bærent Fisker

a.fisker@bandim.org

\section{ABSTRACT}

Purpose Bandim Health Project (BHP) monitors health and survival of women and children in a nationally representative rural Health and Demographic Surveillance System (HDSS) in Guinea-Bissau. The HDSS was set up in 1989-1990 to collect data on health interventions and child mortality.

Participants The HDSS covers 182 randomly selected clusters across the whole country. The cohort is open, and women and children enter the cohort, when they move into the selected clusters, and leave the cohort, when they move out or die, or when children reach 5 years of age. Data are collected through biannual or more frequent household visits. At all village visits, information on pregnancies, vital status, vaccination status, arm circumference, use of bed nets and other basic information is collected for women and children. Today, more than 25000 women and 23000 children below the age of 5 years are under surveillance.

Findings to date Research from the BHP has given rise to the hypothesis that vaccines, in addition to their targeted effects, have important non-specific effects altering the susceptibility to other infections. Initially, it was observed that mortality among children vaccinated with the live BCG or measles vaccines was much lower than the mortality among unvaccinated children, a difference, which could not be explained by prevention of tuberculosis and measles infections. In contrast, mortality tended to be higher for children who had received the non-live Diphtheria-TetanusPertussis vaccine compared with children who had not received this vaccine. Since the effect differed for the different vaccines, no bias explained the contrasting findings. Future plans New health interventions are introduced with little assessment of real-life effects. Through the HDSS, we can describe both the implementation of interventions (eg, the vaccination programme) and their effects. Furthermore, the intensive follow-up allows the implementation of randomised trials testing potential better vaccination programmes.

\section{INTRODUCTION}

Bandim Health Project (BHP) implements a health and demographic surveillance system

\section{Strengths and weaknesses}

- The Bandim Health Project rural Health and Demographic Surveillance System (HDSS) is a nationally representative HDSS covering women and children below the age of 5 years in 182 village clusters all over Guinea-Bissau.

- Since the inception of the HDSS, registration of pregnancies and follow-up for birth outcomes have been at the core of the data collection.

- Vaccination data are collected at all visits allowing for assessment of the real-life effects of vaccines and changes in vaccination policies.

- Six-monthly visits and individual follow-up means that hard endpoints like deaths are not missed but the precision of dates may be limited to month of event.

- Cause of death is established based on an interview conducted at the time of registering the death, thus classified causes must be interpreted with caution.

(HDSS) in Guinea-Bissau, a small West African country located at the coast to the Atlantic Ocean. Guinea-Bissau borders Senegal in the north and Guinea to the east and south. The climate is tropical with an annual rainfall of approximately $1500 \mathrm{~mm}^{1}$ during a single rainy season (June to November).

The BHP rural HDSS in its present form was set up in 1989-1990 with support from Unicef to assess the prevalence of neonatal tetanus and to collect data on child mortality to monitor the impact of a Danish International Development Agency (DANIDA)-sponsored project to strengthen primary healthcare.

The surveillance initially comprised randomly selected village clusters in the five most populous rural regions of Guinea-Bissau (Oio, Biombo, Gabu, Cacheu and Bafata), where $83 \%$ of the rural Guinean population 
lived. The focus was on ensuring accurate data on child mortality and therefore the emphasis was on pregnancy registration, antenatal care and childhood vaccinations. Before the present setup, in 1979-1990, a convenience sample of 20 villages in Biombo, Cacheu, Oio and Tombali was followed; some of the original villages continued as part of the present HDSS.

\section{Cohort description}

The BHP rural HDSS covers women of reproductive age and children below the age of 5 years residing in the clusters. Between 1990 and 2006, the HDSS covered 20 clusters in Oio, Biombo, Gabu, Cacheu and Bafata. The clusters were selected using the method recommended by the Expanded Programme on Immunizations for surveys of immunisation coverage. In all, 20 clusters of 100 women per region were selected based on a listing of the population size. The chance of being selected was proportional to the population size. If the village selected had fewer than 100 women, the closest neighbouring village was included. A third village was added if the sample was still below 100 women.

In 2006, with support from World Bank, two additional rural regions (Tombali and Quinara) with 20 clusters and two regions on the islands (Bubaque and Bolama) with 10 and 12 clusters, respectively, were added. The Cacheu health region was split in two health regions (Cacheu and São Domingos) and therefore 20 clusters were added to the already included clusters in Cacheu. Thus, from 2006 and onwards, the rural HDSS consisted of 182 clusters in the nine rural health regions (figure 1). Details of annual population followed are provided in table 1 .

The clusters are followed through biannual household visits. The surveillance in the rural HDSS has been uninterrupted, except for slightly longer intervals between visits in 1998-1999, due to a civil war. Since September 2007, a nurse who administers vaccines has accompanied the BHP teams. Since 2012, monthly and bimonthly visits have been conducted in the three health regions closest to Bissau (Oio, Biombo and Cacheu). At these more frequent visits, only pregnancies and children below 12 months of age were registered and followed up (figure 2).

The BHP rural HDSS is an open cohort: Girls who have grown up in the village are registered in the cohort of women when they reach 13-15 years of age. New women are registered at the first village visit after they are stated to have moved into the village and remain under surveillance until death or out-migration. Women are followed from date of registration and are considered part of the cohort as long as they state that they live in the village (we do not operate with quarantine periods during which an in-migrant has to remain in the area before being registered, as has been done in other HDSS sites). Children are registered already as fetuses. In-migrating children under 5 years of age are registered when they move into the village. All children are followed from birth or date of registration, whichever comes last. Thus, children registered after birth only enter the cohort from date of registration. All children are followed to death, out-migration or 5 years of age.

While key information on pregnancies, births and deaths has been registered throughout, additional information has been collected for shorter periods as displayed in figure 3 . When a woman is registered, basic information on ethnicity, age, schooling, obstetric history and vaccination scar status is obtained. Since 2011, we have also registered the name of her mother and whether the woman was born in the village, but linkage to child records has not been performed. At registration and subsequent visits, the woman is asked if she is pregnant, whether she has had any births or miscarriages since last visit and use of bed net (figure 3). On registration of a pregnancy, information on antenatal care and gestational age is obtained, and maternal mid-upper-arm circumference (MUAC) is measured. Information on socioeconomic background factors is collected at the first registration of a pregnancy/ child. When registering the pregnancy outcome and at registration of infants, information on antenatal care, tetanus vaccines during pregnancy and place of birth is collected. At all subsequent household visits, information about vaccination status, nutritional status (assessed by MUAC) and hospital admissions is obtained (figure 3). Furthermore, for children under 1 year of age and newly registered children, BCG scar status is assessed. In the regions with shorter intervals between follow-up visits, we also register whether the child has been ill since the last visit, and if the child was taken for outpatient consultation.

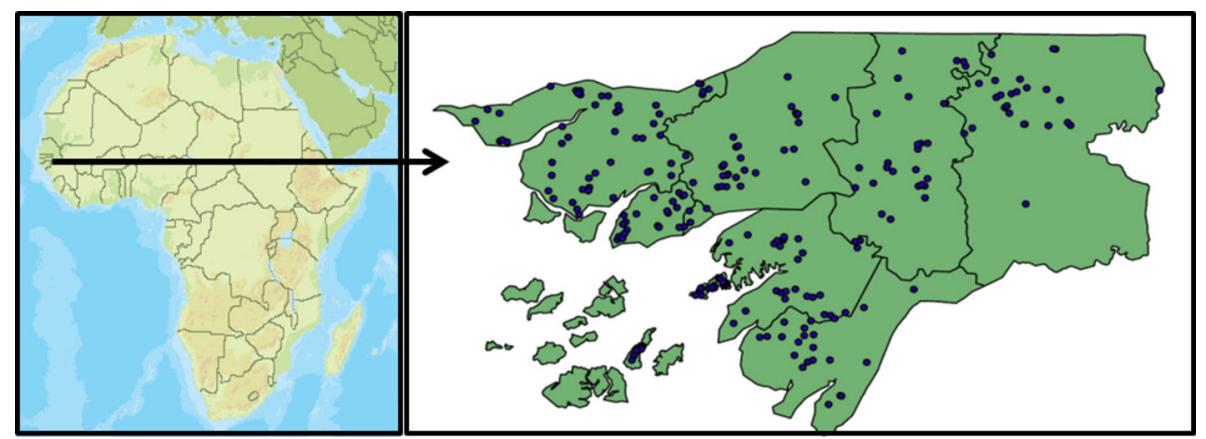

Figure 1 Map of Guinea-Bissau with the HDSS clusters marked as blue dots. HDSS, Health and Demographic Surveillance System. 


\begin{tabular}{|c|c|c|c|c|}
\hline Year & $\begin{array}{l}\text { Number of } \\
\text { pregnancies } \\
\text { registered } \\
\text { before date } \\
\text { of birth }\end{array}$ & $\begin{array}{l}\text { Number } \\
\text { of births } \\
\text { registered* }\end{array}$ & $\begin{array}{l}\text { Total } \\
\text { population } \\
\text { under } 5 \text { years } \\
\text { of age under } \\
\text { surveillance }\end{array}$ & $\begin{array}{l}\text { Total } \\
\text { population } \\
\text { of fertile } \\
\text { women under } \\
\text { surveillance }\end{array}$ \\
\hline 1990 & 1418 & 891 & 1381 & 8852 \\
\hline 1991 & 1796 & 1761 & 3003 & 9624 \\
\hline 1992 & 1697 & 1852 & 4563 & 10000 \\
\hline 1993 & 1769 & 2027 & 6139 & 10479 \\
\hline 1994 & 1774 & 1928 & 7445 & 10643 \\
\hline 1995 & 1722 & 2119 & 8580 & 11109 \\
\hline 1996 & 1896 & 2426 & 10963 & 11896 \\
\hline 1997 & 1916 & 2456 & 11946 & 12395 \\
\hline 1998 & 1013 & 2143 & 10916 & 12090 \\
\hline 1999 & 1635 & 2204 & 11368 & 12368 \\
\hline 2000 & 1874 & 2479 & 11785 & 12556 \\
\hline 2001 & 1786 & 2382 & 11535 & 12659 \\
\hline 2002 & 1705 & 2260 & 11698 & 12667 \\
\hline 2003 & 1741 & 2477 & 11814 & 12949 \\
\hline 2004 & 1785 & 2457 & 12138 & 13169 \\
\hline 2005 & 1608 & 3390 & 12161 & 13193 \\
\hline $2006 \ddagger$ & 2850 & 4114 & 19786 & 22348 \\
\hline 2007 & 2959 & 4134 & 21502 & 22985 \\
\hline 2008 & 2217 & 3923 & 20961 & 22419 \\
\hline 2009 & 2734 & 3908 & 21359 & 22278 \\
\hline 2010 & 2621 & 3948 & 21483 & 22519 \\
\hline 2011 & 3045 & 4120 & 21973 & 23247 \\
\hline 2012 & 3444 & 4462 & 22665 & 23926 \\
\hline 2013 & 3686 & 4343 & 23581 & 24573 \\
\hline 2014 & 3259 & 4257 & 23470 & 24588 \\
\hline 2015 & 2717 & 3996 & 22886 & 24452 \\
\hline 2016 & 3023 & 3844 & 23174 & 25120 \\
\hline 2017 & 2965 & 3948 & 23479 & 25649 \\
\hline
\end{tabular}

*Births registered within first 12 months of live.

†Women aged 13-49 years are considered of reproductive age. Information on age is missing for 380 women.

fUpscaling from 100 to 182 village clusters.

At all visits, vital status is updated for both women and children and a simple verbal autopsy is conducted on registration of a death. The verbal autopsy seeks to distinguish deaths due to accidents and natural causes, and to describe symptoms in the period leading up to death.

The data are collected on paper questionnaires and entered in the BHP offices in Bissau city. Data are entered into tables using a platform build in $\mathrm{dBaseV}$. Following data entry, data are checked for consistency and required corrections are made by consulting the original forms. The data on children under surveillance and registered pregnancies are used to create lists for the next visit with pre-printed of identifying information for pregnant women and all children including their already collected vaccination information. Since we allow neighbours to provide information for women and children who cannot be localised in the villages, our loss to follow-up is very low, but $1 / 5$ children are registered to have migrated out of the village before 5 years of age.

\section{Patient and public involvement}

The communities were involved in locating households, when the HDSS was setup and contributed information allowing tracing of internal migrants within and to some extend between villages. No participants were involved in setting the research question or the outcome measure, nor were they involved in developing plans for recruitment, design or implementation of the study. No participant was asked to advise on interpretation or writing up the results. The results of studies carried out within the HDSS are disseminated to the national public health institute. There are no plans to disseminate results of the research to study participants or the community.

\section{Findings to date}

The rural HDSS has made it possible to obtain accurate estimates of mortality and to evaluate factors related to both maternal ${ }^{23}$ and child mortality ${ }^{4-11}$ in a nationally representative sample of the rural population in Guinea-Bissau. A list of papers based on the rural HDSS data is provided in the online supplementary appendix.

\section{Vaccines and child mortality: non-specific effects of vaccines}

Vaccines are given to protect against targeted diseases, but research from the BHP has given rise to the hypothesis that vaccines, in addition to their targeted effects, have important non-specific effects (NSEs) altering the susceptibility to other infections. Using data from the first years of data collection during the early 1990 s, while the vaccination programme was still being rolled out, a surprising finding was made ${ }^{4}$ : The live BCG and measles vaccination (MV) were associated with beneficial NSEs. The mortality among children vaccinated with BCG or MV was much lower than the mortality among unvaccinated children, a difference, which could not be explained by prevention of tuberculosis and measles infections. In contrast, the opposite tendency was seen for the non-live Diphtheria-Tetanus-Pertussis (DTP) vaccine. Since the effect was different for the different vaccines, no bias explained the contrasting findings.

Following the surprising finding on DTP, WHO reviewed the data collection and the data management, and found no sources of bias that could invalidate the study. ${ }^{12}$ To further examine the possible deleterious effects of DTP, WHO sponsored a series of re-analyses of existing datasets on vaccinations from other cohorts. ${ }^{13-17}$ All studies found beneficial effects of DTP on child survival. Unfortunately, these studies introduced major bias in the analyses. First, children were not excluded for lack of information on vaccination status; in a setting with no public registers, information is not available for all children. A reason 


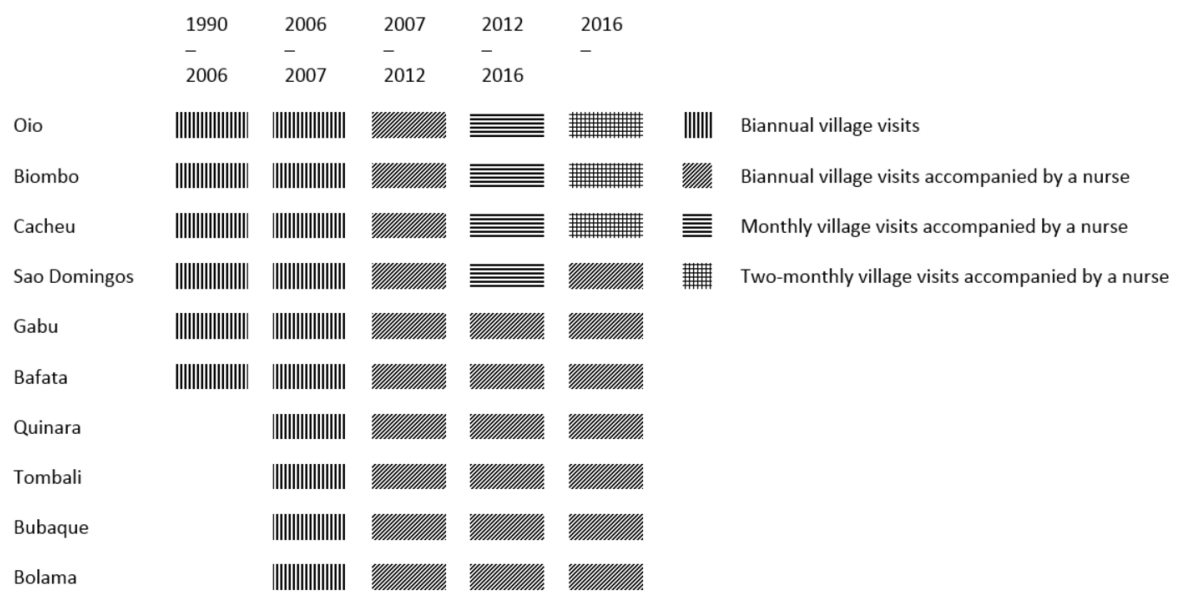

Figure 2 Visit frequency by period and health region.

for getting no information is that the child has already died, thus some dead, vaccinated children will be selectively misclassified as 'unvaccinated', skewing the results. Second, whereas the BHP studies had only counted survival time from the day the vaccination card had been inspected, the WHO-sponsored studies retrospectively updated vaccination status from the date of vaccination, thus allocating risk-free survival time to children from date of vaccination until the day the vaccination card was inspected. The implications of these methodological flaws were major; BHP could show that if we analysed our own data the same way as WHO-sponsored studies had done, we would get the same 'faulty' beneficial effects of DTP. ${ }^{18}$ This led to a discussion on prospective follow-up,

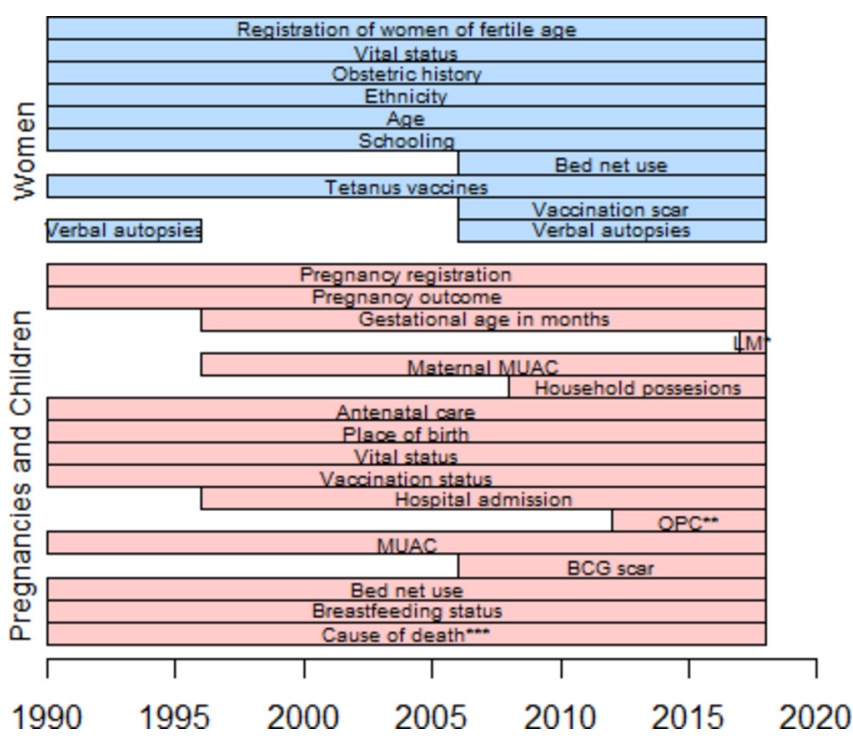

Figure 3 Gantt diagram of data collected through the BHP rural HDSS Note: *LM: last menstrual period ${ }^{* \star} O P C$ : outpatient consultations ${ }^{* \star *}$ symptoms of disease leading up to death registered throughout. Further details collected through a verbal autopsy since 2005. BHP, Bandim Health Project; HDSS, Health and Demographic Surveillance System. which has defined the standard for later studies of the impact of vaccinations on child survival. ${ }^{18-21}$

The findings of beneficial NSEs of BCG and MV and negative NSEs of DTP have later been confirmed in many other settings ${ }^{22}$ including the clusters followed in rural Guinea-Bissau before $1990 .^{23}$ A key feature of the NSEs is that the effects frequently differ for boys and girls, with girls obtaining larger benefit from receiving live $\mathrm{MV},{ }^{622425}$ but also stronger negative effects of receiving DTP. ${ }^{26} 27$ This emphasises the need to assess effects of health interventions by sex. Studies of the NSEs of vaccines and other health interventions have defined much of the research agenda at the BHP.

\section{Declining mortality levels and possible explanations: vaccination campaigns}

Mortality for children in the rural HDSS has declined by almost two-thirds between 1990 and 2013, and according to the verbal autopsies performed since 2005, the main cause of death is malaria. ${ }^{9}$ Part of the reduction may be ascribed to vaccination campaigns conducted with short intervals during the last two decades. MV campaigns are conducted to ensure that children receive the second dose of MV. We used the HDSS data to assess the effects of a general MV campaign in rural Guinea-Bissau, ${ }^{7}$ and found that the MV campaign was associated with a $20 \%$ ( $95 \%$ CI: $4 \%$ to $34 \%$ ) reduction in mortality rate.

\section{Mortality of women of reproductive age}

In contrast to the marked reduction in child mortality, mortality of women of reproductive age has declined little over the past 28 years ${ }^{3}$. Research with a focus on levels and causes of death indicate that mortality of women below the age of 50 years remains high at around 750/100 000 person years; one-third of these deaths is related to pregnancy and childbirth. ${ }^{28-30}$

Implementation and evaluation of the vaccination programme Vaccines are available at the government health centres and since 2008 frequently also through outreach to 
villages further away from the health centres. ${ }^{6}$ The HDSS enables us to describe both the implementation of the vaccination programme and its effect. Vaccination coverage estimates are commonly based on number of vaccines given to children below 12 months divided by the estimated population of infants surviving past infancy. The estimated target population of children based on projected census data carries much uncertainty, and coverage estimates are therefore not very precise and may exceed $100 \%$. Using the rural HDSS data, we have been able to precisely measure vaccination coverage ${ }^{63132}$ based on vaccination coverage among those with assessed vaccination status (seen vaccination card or never vaccinated).

The coverage of the third dose of the DTP-containing vaccine by 12 months of age is one of the main indicators of the vaccination programme. This indicator may not contribute to the optimal implementation of the vaccination programme: When the pentavalent vaccine (DTP, Hepatitis B and Haemophilus Influenzae type B) was introduced in the vaccination programme, ${ }^{6}$ we evaluated the impact. The introduction of the new vaccine was accompanied by increased vaccination outreach services and a more restrictive wastage policy. We found that the proportion of fully vaccinated children did not change (risk ratio $1.00 ; 95 \%$ CI: 0.89 to 1.11 ), but interestingly the coverage of DTP3 increased from $73 \%$ in 2007 to $81 \%$ in 2009 , whereas the MV coverage declined from $71 \%$ in 2007 to $66 \%$ in 2009. Bearing in mind that previous research had shown beneficial NSEs of MV, whereas DTP-containing vaccine was associated with negative NSEs, this shift may have had important negative consequences. ${ }^{6}$

In 2014, a WHO commissioned review evaluated the evidence of NSEs of BCG, MV and DTP, and concluded that the live BCG and MV were associated with beneficial NSEs. ${ }^{22}$ No alterations to the vaccination programme were recommended, but a call for more research was issued. ${ }^{22}$ Though vaccinations are recommended at specific ages, BHP data demonstrate that there is a large gap between the recommendations and the implemented vaccination programme. Part of the explanation is the focus on vaccine wastage as a performance indicator complementing the 12-month vaccination coverage. This has led to a national policy of not opening a vial of BCG or MV unless sufficient children are present for vaccination because the vaccines come in multi-dose vials, which have to be discarded within 6 hours after reconstitution. We have shown that disregarding the policy of only opening a vial if sufficient children are present for vaccination can increase vaccine coverage. ${ }^{32}{ }^{33}$ We have furthermore been able to show that it is highly cost-effective to open a multidose vial of MV even for one child ${ }^{33}$ : already at a wastage rate of $88 \%$ it was cost saving to vaccinate all children with MV.

Building on to our assessment of the measured reallife effects of vaccines, we have investigated alternative indicators of vaccination programme effectiveness. Based on our findings, the programme should emphasise timeliness of vaccines, especially of the live vaccines that are administered as one dose in the routine vaccination programme. Furthermore, post-vaccination BCG scar should be an indicator: If BCG vaccines are given correctly, then they result in the formation of a BCG scar in approximately $90 \%$ of cases. ${ }^{34-36}$ Using data from the rural HDSS, we found that only $52 \%$ of children vaccinated through the routine vaccination programme in Guinea-Bissau had a BCG scar, and we could show that among BCG-vaccinated children, having a BCG scar was associated with lower mortality. ${ }^{8}$

\section{Randomised trials in the BHP rural HDSS}

The HDSS setup allows the nesting of individually and cluster-randomised trials. In 2007-2011, we tested the effect of vitamin A supplementation at vaccination contacts. ${ }^{5}$ Subsequently, we have implemented cluster-randomised and individually randomised trials testing potential benefits of altering the vaccination schedule and its implementation $^{37} 38$ (table 2). Since we have no control areas with no trial implementation, we cannot make strong conclusions on the impact of the trials on the child mortality level in the villages. However, in the past trials, only a small subset of children has been enrolled. ${ }^{538}$

At present, less than half of the children in rural Guinea-Bissau receive BCG vaccine in the first month of life. ${ }^{32}$ We are conducting a cluster-randomised trial of providing BCG and oral polio vaccination (OPV) vaccines within 3 days of birth to children in rural Guinea-Bissau. ${ }^{39}$ The study will evaluate the effect of BCG and OPV on early infant mortality, and will furthermore be a proof-of-concept of whether it is possible to deliver vaccines at birth in a rural setting, where many women do not deliver at health centres.

We are also testing the effects of campaigns with live MV and OPV in randomised trials. ${ }^{40}$ Polio and measles infections are about to be eradicated and the vaccination campaigns are therefore likely to be stopped. Since the vaccination campaigns may be associated with survival benefits beyond what can be explained by the prevention of polio ${ }^{41}{ }^{42}$ and measles, ${ }^{73}$ we conduct two cluster-randomised trials assessing the campaign effects. In these trials, HDSS villages have been randomised to receive a vaccination campaign or not receiving a vaccination campaign. The first trial assesses the effect of OPV campaigns among children aged 0-8 months of age, and the second trial is assessing the effect of measles campaigns among children aged 9-59 months of age. ${ }^{40}$

\section{Strengths and limitations}

The emphasis on pregnancy registration throughout the data collection period allows accurate data on early mortality over the past 28 years, but we do not presume to have information on the exact number of births, which have occurred in the registered households. The nationally representative village clusters, and the individual-level registration of preventive health interventions received, enable us to evaluate the real-life implementation and effects of new interventions. 


\begin{tabular}{|c|c|c|c|c|c|}
\hline Trial & Objective & Year of trial & $\begin{array}{l}\text { Enrolment ages } \\
\text { and criteria }\end{array}$ & $\begin{array}{l}\text { Number of } \\
\text { children enrolled/ } \\
\text { planned to be } \\
\text { enrolled }\end{array}$ & $\begin{array}{l}\text { Trial registration ID } \\
\text { at clinicaltrials.gov }\end{array}$ \\
\hline $\begin{array}{l}\text { Evaluation of the impact on } \\
\text { mortality and morbidity of the } \\
\text { WHO recommended vitamin } \\
\text { A supplementation at first } \\
\text { immunisation contact after } \\
6 \text { months of age }\end{array}$ & $\begin{array}{l}\text { To assess the effect of providing vitamin } A \\
\text { supplementation at vaccination contacts } \\
\text { after } 6 \text { months of age }\end{array}$ & 2007-2011 & $\begin{array}{l}6-23 \text { months, } \\
\text { missing one or } \\
\text { more routine } \\
\text { vaccines }\end{array}$ & 7587 & NCT00514891 \\
\hline $\begin{array}{l}\text { The effect on overall mortality of } \\
\text { a national policy of limiting MV } \\
\text { to children below } 12 \text { months of } \\
\text { age }^{3337}\end{array}$ & $\begin{array}{l}\text { To assess the effect on mortality and } \\
\text { hospitalisations of providing MV to all } \\
\text { MV-unvaccinated children between } \\
9 \text { and } 35 \text { months of age disregarding the } \\
\text { national policy of restricting the opening } \\
\text { of MV vials }\end{array}$ & 2011-2016 & $\begin{array}{l}\text { 9-35 months, } \\
\text { measles } \\
\text { unvaccinated }\end{array}$ & 4476 & NCT01306006 \\
\hline $\begin{array}{l}\text { A two-site-randomised trial of } \\
\text { an additional measles vaccine at } \\
4 \text { months of age to reduce child } \\
\text { mortality in rural areas of Burkina } \\
\text { Faso and Guinea-Bissau }\end{array}$ & $\begin{array}{l}\text { To assess the effect on child survival of a } \\
\text { two-dose MV schedule by providing an } \\
\text { additional dose of Edmonston-Zagreb } \\
\text { measles vaccine as soon as possible after } \\
4 \text { months of age as well as the standard } \\
\text { measles vaccine at } 9 \text { months of age. }\end{array}$ & $2012-2016$ & $\begin{array}{l}4-7 \text { months, } \\
\text { received penta3 } \\
\text { at least } 4 \text { weeks } \\
\text { previously }\end{array}$ & 3750 & NCT01644721 \\
\hline $\begin{array}{l}\text { Can earlier BCG vaccination } \\
\text { reduce early infant mortality? A } \\
\text { cluster-randomised trial }^{39}\end{array}$ & $\begin{array}{l}\text { To assess the effect of BCG and OPV } \\
\text { provided at a single home visit within } \\
72 \text { hours after birth on early infant } \\
\text { mortality and morbidity. }\end{array}$ & 2015-2020 & $\begin{array}{l}\text { 0-3 days, BCG } \\
\text { unvaccinated, } \\
\text { registered in the } \\
\text { HDSS during } \\
\text { pregnancy }\end{array}$ & 6666 & NCT02504203 \\
\hline $\begin{array}{l}\text { The effect of a MV campaign on } \\
\text { morbidity and mortality among } \\
\text { children aged 9-59 months in } \\
\text { rural Guinea-Bissau-a cluster- } \\
\text { randomised controlled trial }\end{array}$ & $\begin{array}{l}\text { To assess the effect of a MV campaign on } \\
\text { mortality and morbidity }\end{array}$ & 2016-2019 & $\begin{array}{l}9-59 \text { months, not } \\
\text { enrolled in the OPV } \\
\text { campaign trial }\end{array}$ & 18000 & NCT03460002 \\
\hline $\begin{array}{l}\text { A cluster-randomised controlled } \\
\text { trial of the effect of oral polio } \\
\text { vaccine campaigns on child } \\
\text { morbidity and mortality } 40\end{array}$ & $\begin{array}{l}\text { To assess the effect of OPV campaigns on } \\
\text { morbidity and mortality in Guinea-Bissau } \\
\text { in a context with no polio }\end{array}$ & $\begin{array}{l}2017-2020 \\
\text { (anticipated) }\end{array}$ & $0-8$ months & 10000 & NCT03460002 \\
\hline
\end{tabular}

HDSS, Health and Demographic Surveillance System; MV, measles vaccination; OPV, oral polio vaccination.

The data are collected through household visits by experienced fieldwork assistants, many of whom have worked for the BHP for years; thus, they are very familiar with all aspects of data collection. The close collaboration with the local and national health authorities ensures that findings from the BHP rural HDSS are passed on to the health authorities. The long-standing relation with the population under surveillance enables the collection of important and at times sensitive information.

Conducting demographic surveillance in a highly mobile population is possible because family members provide information on the whereabouts of the travelling individuals. Not operating with periods of quarantine allows unbiased mortality estimates, also for migrants.

Only a quarter of the deaths occur in health facilities, and even for deaths in facilities, the diagnostic information is limited. Hence, in a rural population where many do not seek healthcare even for severe illness, and where little information is provided by the health staff to those who do, we seldom obtain diagnosis for admissions or causes of death. We seek to assess the cause of death based on the described symptoms obtained from a short interview conducted when a death is registered, but classified causes must be interpreted with caution.
With 6-monthly visits, the recall period becomes long, and dates may be subject to some uncertainty. We rarely are able to obtain full information on, for example, vaccines received for children who have died between two rounds of visits. To avoid selectively misclassifying observation time, we therefore only rely on the landmark approach $^{18}$ in our analyses, emphasising the prospective follow-up from the date of registration of vaccination rather than retrospective update of vaccination status.

The 6-monthly visits make it unlikely that hard endpoints like death should be subject to bias, but other endpoints could be influenced by bias. More frequent visits in some regions increase the precision.

Acknowledgements We are grateful to field teams, field supervisors, data entry and data cleaning assistants, management and administration staff at the Bandim Health Project for their dedicated work in implementing the health and demographic surveillance system. We thank the population in the surveyed villages and regional health authorities for receiving our teams and patiently answering all the questions. A special thank you to Joaquim Gomes, Francisco Indi, Mariano da Gama and Jorge Sami for their work in initiating the surveillance system in 19891990 and to Dr Amabelia Rodrigues for upscaling the surveillance to comprise all regions in 2006.

Contributors PA established the surveillance and implemented the original census in collaboration with MF. SMT and ABF now manage the surveillance and drafted the article. MF, CSB and PA were involved in critical revision of the article. All authors were involved in final approval of the article. 
Funding BHP has no core funding and the past 28 years of data collection has been financed through grants from many different funders. The original censuses were funded by UNICEF and World Bank.

Map disclaimer The depiction of boundarieson the map(s) in this article do not imply the expression of any opinionwhatsoever on the part of BMJ (or any member of its group) concerning the legalstatus of any country, territory, jurisdiction or area or of its authorities.The map(s) are provided without any warranty of any kind, either express orimplied.

Competing interests None declared.

Patient consent for publication Not required

Provenance and peer review Not commissioned; externally peer reviewed.

Data sharing statement Data from the BHP's rural HDSS can be made available on a collaborative basis (www.bandim.org).

Open access This is an open access article distributed in accordance with the Creative Commons Attribution Non Commercial (CC BY-NC 4.0) license, which permits others to distribute, remix, adapt, build upon this work non-commercially, and license their derivative works on different terms, provided the original work is properly cited, appropriate credit is given, any changes made indicated, and the use is non-commercial. See: http://creativecommons.org/licenses/by-nc/4.0/.

\section{REFERENCES}

1. The World Bank Group. Climate Change Knowlegde Portal. For Development Practitioners and Policy Makers 2016. 2018 http:// sdwebx.worldbank.org/climateportal/index.cfm?page=country historical climate\&ThisCCode=GNB (accessed 21 Jun 2018).

2. Høj L, da Silva D, Hedegaard K, et al. Factors associated with maternal mortality in rural Guinea-Bissau. A longitudinal populationbased study. BJOG 2002;109:792-9.

3. Mane M, Fisker AB, Ravn $\mathrm{H}$, et al. Trends and determinants of mortality in women of reproductive age in rural Guinea-Bissau, West Africa--a cohort study. BMC Womens Health 2013;13:48.

4. Kristensen I, Aaby P, Jensen H. Routine vaccinations and child survival: follow up study in Guinea-Bissau, West Africa. BMJ 2000;321:1435-8.

5. Fisker $A B$, Bale $C$, Rodrigues $A$, et al. High-dose vitamin A with vaccination after 6 months of age: a randomized trial. Pediatrics 2014;134:e739-e748.

6. Fisker AB, Hornshøj L, Rodrigues A, et al. Effects of the introduction of new vaccines in Guinea-Bissau on vaccine coverage, vaccine timeliness, and child survival: an observational study. Lancet Glob Health 2014;2:e478-e487.

7. Fisker AB, Rodrigues A, Martins C, et al. Reduced All-cause Child Mortality After General Measles Vaccination Campaign in Rural Guinea-Bissau. Pediatr Infect Dis J 2015;34:1369-76.

8. Storgaard L, Rodrigues A, Martins C, et al. Development of BCG Scar and Subsequent Morbidity and Mortality in Rural GuineaBissau. Clin Infect Dis 2015;61:950-9.

9. Nielsen BU, Byberg S, Aaby P, et al. Seasonal variation in child mortality in rural Guinea-Bissau. Trop Med Int Health 2017;22:846-56.

10. Aaby P, Bukh J, Lisse IM, et al. Overcrowding and intensive exposure as determinants of measles mortality. Am J Epidemiol 1984;120:49-63.

11. Aaby P, Andersen M, Sodemann M, et al. Reduced childhood mortality after standard measles vaccination at 4-8 months compared with 9-11 months of age. BMJ 1993;307:1308-11.

12. Mulholland K, Barreto ML. Routine vaccination and child survival in Guinea-Bissau. Lessons can be learnt from this study. BMJ 2001;322:360-60.

13. Elguero E, Simondon KB, Vaugelade J, et al. Non-specific effects of vaccination on child survival? A prospective study in Senegal. Trop Med Int Health 2005;10:956-60.

14. Vaugelade J, Pinchinat S, Guiella G, et al. Non-specific effects of vaccination on child survival: prospective cohort study in Burkina Faso. BMJ 2004;329:1309.

15. Lehmann D, Vail J, Firth MJ, et al. Benefits of routine immunizations on childhood survival in Tari, Southern Highlands Province, Papua New Guinea. Int J Epidemiol 2005;34:138-48.

16. Breiman RF, Streatfield PK, Phelan M, et al. Effect of infant immunisation on childhood mortality in rural Bangladesh: analysis of health and demographic surveillance data. Lancet 2004;364:2204-11.
17. Moulton LH, Rahmathullah L, Halsey NA, et al. Evaluation of nonspecific effects of infant immunizations on early infant mortality in a southern Indian population. Trop Med Int Health 2005;10:947-55.

18. Jensen H, Benn CS, Lisse IM, et al. Survival bias in observational studies of the impact of routine immunizations on childhood survival. Trop Med Int Health 2007;12:5-14.

19. Farrington CP, Firth MJ, Moulton LH, et al. Epidemiological studies of the non-specific effects of vaccines: II--methodological issues in the design and analysis of cohort studies. Trop Med Int Health 2009;14:977-85.

20. Fine PE, Smith PG. 'Non-specific effects of vaccines'--an important analytical insight, and call for a workshop. Trop Med Int Health 2007;12:1-4.

21. Aaby P, Benn CS, Nielsen J, et al. DTP vaccination and child survival in observational studies with incomplete vaccination data. Trop Med Int Health 2007;12:15-24.

22. Higgins JP, Soares-Weiser K, López-López JA, et al. Association of BCG, DTP, and measles containing vaccines with childhood mortality: systematic review. BMJ 2016;355:i5170.

23. Aaby $\mathrm{P}$, Jensen $\mathrm{H}$, Gomes J, et al. The introduction of diphtheriatetanus-pertussis vaccine and child mortality in rural Guinea-Bissau: an observational study. Int J Epidemiol 2004;33:374-80.

24. Aaby P, Martins CL, Garly ML, et al. Non-specific effects of standard measles vaccine at 4.5 and 9 months of age on childhood mortality: randomised controlled trial. BMJ 2010;341:c6495.

25. Aaby $P$, Jensen $H$, Rodrigues $A$, et al. Divergent female-male mortality ratios associated with different routine vaccinations among female-male twin pairs. Int J Epidemiol 2004;33:367-73.

26. Aaby P, Benn C, Nielsen J, et al. Testing the hypothesis that diphtheria-tetanus-pertussis vaccine has negative non-specific and sex-differential effects on child survival in high-mortality countries. BMJ Open 2012;2:e000707.

27. Aaby $\mathrm{P}$, Ravn $\mathrm{H}$, Fisker $\mathrm{AB}$, et al. Is diphtheria-tetanus-pertussis (DTP) associated with increased female mortality? A meta-analysis testing the hypotheses of sex-differential non-specific effects of DTP vaccine. Trans $R$ Soc Trop Med Hyg 2016;110:570-81.

28. Høj L, Stensballe J, Aaby P. Maternal mortality in Guinea-Bissau: the use of verbal autopsy in a multi-ethnic population. Int J Epidemiol 1999;28:70-6.

29. Høj L, da Silva D, Hedegaard K, et al. Maternal mortality: only 42 days? BJOG 2003;110:995-1000.

30. Mane M. Mortality of women of fertile age and maternal mortality. University of Copenhagen 2014.

31. Hornshøj L, Benn CS, Fernandes M, et al. Vaccination coverage and out-of-sequence vaccinations in rural Guinea-Bissau: an observational cohort study. BMJ Open 2012;2:e001509-e09.

32. Thysen SM, Byberg S, Pedersen M, et al. BCG coverage and barriers to BCG vaccination in Guinea-Bissau: an observational study. BMC Public Health 2014;14:1037.

33. Byberg S, Fisker AB, Thysen SM, et al. Cost-effectiveness of providing measles vaccination to all children in Guinea-Bissau. Glob Health Action 2017:10:1329968.

34. Roth $A$, Sodemann M, Jensen $\mathrm{H}$, et al. Vaccination technique, PPD reaction and BCG scarring in a cohort of children born in GuineaBissau 2000-2002. Vaccine 2005;23:3991-8.

35. Funch KM, Thysen SM, Rodrigues A, et al. Determinants of BCG scarification among children in rural Guinea-Bissau: A prospective cohort study. Hum Vaccin Immunother 2018;14:2434-42.

36. Frankel H, Byberg S, Bjerregaard-Andersen M, et al. Different effects of BCG strains - A natural experiment evaluating the impact of the Danish and the Russian BCG strains on morbidity and scar formation in Guinea-Bissau. Vaccine 2016;34:4586-93.

37. Byberg S, Fisker AB, Rodrigues A, et al. Household experience and costs of seeking measles vaccination in rural Guinea-Bissau. Trop Med Int Health 2017;22:12-20.

38. Fisker AB, Nebie E, Schoeps A, et al. A Two-Center Randomized Tria of an Additional Early Dose of Measles Vaccine: Effects on Mortality and Measles Antibody Levels. Clin Infect Dis 2018;66:1573-80.

39. Thysen SM, Jensen AKG, Rodrigues A, et al. Can earlier BCG vaccination reduce early infant mortality? Study protocol for a cluster randomised trial in Guinea-Bissau (In revision).

40. Varma A, Jensen AKG, Thysen SM, et al. Research protocol of two concurrent cluster randomized trials: Real-life Effects of a CAMPaign with Measles Vaccination (RECAMP-MV) and Real-life Effects of a CAMPaign with Oral Polio Vaccination (RECAMP-OPV) on mortality and morbidity among children in rural Guinea-Bissau (Submitted).

41. Andersen A, Fisker AB, Rodrigues $A$, et al. National Immunization Campaigns with Oral Polio Vaccine Reduce All-Cause Mortality: A Natural Experiment within Seven Randomized Trials. Front Public Health 2018:6:13. 
42. Byberg S, Østergaard MD, Rodrigues A, et al. Analysis of risk factors for infant mortality in the 1992-3 and 2002-3 birth cohorts in rural Guinea-Bissau. PLoS One 2017;12:e0177984.
43. Byberg S, Thysen SM, Rodrigues A, et al. A general measles vaccination campaign in urban Guinea-Bissau: Comparing child mortality among participants and non-participants. Vaccine 2017;35:33-9. 